\title{
Advance Care Planning: practicalities, legalities, complexities and controversies
}

\author{
Karen A Horridge
}

Correspondence to Dr Karen A Horridge, Paediatric Disability Department, Sunderland Royal Hospital, Kayll Rd, Sunderland SR4 7TP, UK; karen.horridge@nhs.net

\section{Received 7 April 2014} Revised 6 September 2014 Accepted 19 September 2014 Published Online First 1 October 2014

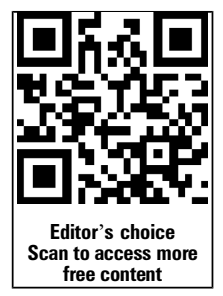

\section{ABSTRACT}

Increasing numbers, complexities and technology dependencies of children and young people with lifelimiting conditions require paediatricians to be well prepared to meet their changing needs. Paediatric Advance Care Planning provides a framework for paediatricians, families and their multidisciplinary teams to consider, reflect and record the outcome of their conversations about what might happen in the future in order to optimise quality of clinical care and inform decision-making. For some children and young people this will include discussions about the possibility of death in childhood. This may be unexpected and sudden, in the context of an otherwise active management plan or may be expected and necessitate discussions about the process of dying and attention to symptoms. Decision-making about appropriate levels of intervention must take place within a legal and ethical framework, recognising that the UK Equality Act (2010) protects the rights of disabled children and young people and infants and children of all ages to the same high quality healthcare as anyone else.

\section{INTRODUCTION}

This article sets out to:

- Describe paediatric Advance Care Planning (pACP) and its various elements;

- Discuss the evidence to support pACP;

- Give pragmatic guidance about pACP for paediatricians based on extensive personal experience;

- Discuss the tricky areas of prognostication and decision-making about appropriate levels of intervention that underpin pACP.

\section{WHAT IS PAEDIATRIC ADVANCE CARE PLANNING AND WHY DO IT?}

Advance Care Planning (ACP) has different meanings depending on perspective of country and legislation. ${ }^{1}$ In broad terms it is a description of the process of discussing issues and planning ahead in anticipation of a change in condition in future. The components of pACP for some families will include discussions about the possibility of premature death. If these conversations are not had, families will miss out on opportunities to state their wishes for aspects of care and interventions, including place of care and preferred place of death. ${ }^{2}$ Clinician-led discussions about the possibilities of dying and death in advance may help families to communicate among themselves about what may otherwise have remained unspoken, may help with the grieving process and improve realistic hope and resilience. $^{3}$

\section{WHAT IS THE EVIDENCE TO SUPPORT ADVANCE CARE PLANNING IN PAEDIATRIC CLINICAL PRACTICE?}

The prevalence of life-limiting conditions in children is increasing, ${ }^{4}$ bringing an increasing clinical need to recognise when dying and death may be possibilities, so that appropriate discussions can be had with families. Balanced against a dearth of randomised, controlled trials in the area of pACP, ${ }^{5} 6$ decision-making about appropriate levels of intervention and end-of-life care for children, ${ }^{i}$ there are plenty of qualitative and descriptive publications evidencing good clinical practice. The Royal College of Paediatrics and Child Health is currently updating their guidance on decision-making for children with life-limiting conditions and the National Institute for Health and Care Excellence (NICE) in England is planning a clinical guideline on end-of-life care in children, both eagerly anticipated; it will be interesting to see how much evidence their rigorous processes identify.

One key message from the literature is without doubt: planning and care for children at risk of premature death needs to improve. A systematic review (2013) reported on three pACP programmes in the USA, two developed from adult programmes. ${ }^{1}$ These involved discussions with families in advance, involvement of chaplains and recording of 'advance directives'. Preliminary findings were that pACP can be implemented and was perceived as helpful. A randomised controlled trial specific to HIV-infected adolescents ${ }^{5}$ showed pACP to trigger positive emotional experiences in young people and their carers with less negative reactions when compared with those in the study's control arm not receiving pACP, also a better communication experience and marginally improved certainty about decisions in the intervention group. ${ }^{57} \mathrm{~A}$ subsequent randomised controlled trial of family centered pACP in young people with cancer concluded that those receiving $\mathrm{pACP}$ were significantly better informed about end-of-life decisions and the young people were more likely to allow family members to 'do what is best at the time' $(100 \%)$ compared with the control group who did not receive pACP $(62 \%) .{ }^{6}$ Those in the pACP group were significantly more likely to limit treatments, knowing that this accorded with the young person's own wishes.

Consistently across studies young people and their carers wanted more information and to be involved in decision-making. ${ }^{7-12}$ Reported barriers to pACP included lack of many children's capacity

i'Children' is used throughout the article as synonymous with 'children and young people' 
to be involved in decision-making themselves, the high degree of prognostic uncertainty, unrealistic expectations of parents, doctors' worries about removing hope and complexity of the social environment. ${ }^{13-15}$ In one study $71 \%$ of doctors questioned thought pACP happened too late. ${ }^{15}$ No studies compared frequency of home deaths in children with and without pACP, but two studies suggest home deaths may be more frequent where pACP had occurred. ${ }^{16} 17$

A study on Birmingham's paediatric intensive care unit captured views of eight consultants and six senior nurses. ${ }^{18}$ They felt that children were 'enduring' intensive care which they believed to be 'futile' and expressed the view that pACP was lacking, but if implemented would improve care for children with life-limiting conditions.

\section{ELEMENTS OF PAEDIATRIC ADVANCE CARE PLANNING Emergency healthcare planning}

It is good clinical practice to provide for families with children with complex healthcare needs a written care plan that includes information about their diagnoses, active health concerns and any emergency scenarios that can be predicted to arise, including written guidance about what to do from presentation in the community through to the hospital emergency department (see figure 1). This is promoted in the UK through 'Together for Short Lives' (http://www.togetherforshortlives.org.uk) who have many helpful supporting resources for families and professionals. A national survey of UK paediatric intensive care units found wide variation in availability and nature of formal pACP documents and called for development of national policy informed by review and evaluation of existing documents and current practice in pACP. ${ }^{19}$

In 2011, the Department of Health (England) funded a collaboration of paediatricians representing general, community, emergency, disability and palliative care paediatrics who together with the Council for Disabled Children agreed core principles for Emergency Health Care Plans. It was acknowledged that localities required their own easily recognisable formats for such Plans across services, including Ambulance Services. The outputs from this work, including e-Learning resources, regional exemplar templates, a parent information leaflet and video exemplars of enacted difficult conversations with families can be found at: http://www. councilfordisabledchildren.org.uk/ehp.

\section{Advance statement of wishes and preferences}

Fraser and team from Bristol have led on this work in the UK. ${ }^{20}$ Practical templates, flow charts and resources are accessible at http://www.togetherforshortlives.org.uk/professionals/external resources/

\section{Statement about discussions with the child and parents about appropriate levels of intervention and the circumstances in which these will apply}

This is the trickiest area, as there is a need for the paediatrician to have discussed the issue of prognosis with the child, their parents or guardians. Prognostication can be extremely difficult; it falls into two broad groups:

- Risk of sudden and unexpected premature death in childhood

- There is evidence that children with long-term conditions are at higher risk than others of sudden and unexpected death. ${ }^{4}$ Paediatricians are not universally confident about discussing this risk with families ${ }^{9} 151819$ but increasingly need to see this as part of their role.
- Paediatricians may be familiar with the concept of Sudden Unexpected Death in Epilepsy. Recent evidence suggests that it is the complexity of the child's disabilities rather than the epilepsy itself that is the main risk factor for sudden death. ${ }^{21}$ There is also evidence especially from support groups (eg, http://www.epilepsyaction.org.uk ; http://www.sudep.org) that families deal better with their loss and grief if there had been a discussion about risk of death in advance. Thus paediatricians caring for children with long-term conditions, especially those with complex disabilities, need to consider the possibility of death and discuss risks openly with families. Discussing the possibility of death does not mean that active treatment should cease. It should never be assumed that early death is inevitable and pACP always needs to embrace a range of possible outcomes.

- Clinicians should be mindful of the improved survival opportunities for even those with complex disabilities, who may not follow the journey predicted for their condition in the published literature and who may respond well to intensive care to tide them over episodes of acute illness. The multifaceted needs of the child should continue to be addressed, based on best evidence, aiming always for the best possible quality of life and fullest possible participation in everyday activities. ${ }^{22}$

- The mode of death in the sudden, unexpected group is as it says on the tin and can occur at any time, in any setting, most usually at night. Families need to be sensitively made aware of this, while setting the risk in context and not making them overanxious.

- Risk of gradual decline, dying and death

- Identifying this group requires the paediatrician to be alert for 'red flags' that the dying process may be imminent or occurring. Some suggested 'red flags' from personal experience are listed in figure 2.

- Children at risk include those:

for whom active treatment is no longer effective and/or the disease process is progressing;

with an underlying static medical condition, usually neurological, chromosomal or genetic, where secondary complications develop their own momentum, unchecked by best efforts of medical interventions.

- The conversation with families about risks of dying and death for this group is necessarily different, as the clinician is sensitively letting the family know that death is expected, although the precise timing of death cannot be predicted and even the frailest children continue to surprise us with their remarkable resilience.

- It should be acknowledged by the clinician that resuscitation attempts are likely to be unsuccessful and that further active treatments are likely to be futile; both may be burdensome for the child and distressing for the family. This needs to be recorded on the family held care plan so that the lead clinician at all times is appraised of what has been discussed and with whom.

- Having a conversation with a family about the possibilities of dying and death is difficult for all involved and requires careful thought and preparation. Some tips from personal experience to consider are given in figure 3 .

- If death is inevitable in the clinical judgment of the lead clinician and a decision is made that further life-sustaining treatment is inappropriate and would be burdensome, there are a number issues to take into account, including in any pACP documentation (see figure 4). 
Figure 1 Component elements of paediatric Advance Care Planning.

\section{Emergency health care planning}

(http://www.councilfordisabledchildren.org.uk/ehp)

- Include demographic data about child or young person and their family

- List active health concerns and diagnoses

- List current treatments or signpost to where these may be found

- Predict specific scenarios that may arise for the individual child or young person and practical guidance to follow, from community setting through to hospital emergency department

- Give details of involved clinicians, including who to contact in an emergency

Advance statement of wishes and preferences ${ }^{19}$

- Include specific wishes and preferences of the child or young person and their parents or carers

- These may include:

- specific people to contact in specific circumstances

- preferred place of care

- any other details that are important to the child or young person and family that they want to be transparently available in a healthcare emergency or in case of change in condition

Statement about discussions with the child and family about appropriate levels of intervention and the circumstances in which these will apply

- For most children and young people this will state that assessment and management should follow Advanced Paediatric Life Support (APLS) guidance at all times, including full resuscitation and intensive care if required. This protects the right of a disabled child to receive the same high standard of healthcare as anyone else and mitigates for a clinician who may be unfamiliar with them from making decisions based on their own preconceived ideas about their quality of life ${ }^{22}$.

- For a minority of children and young people where death is predicted soon as a consequence of a progressive disease process or treatment failure, or where their condition is so very frail as to make resuscitation attempts unlikely to succeed, a statement to the effect that the child or young person should be allowed a natural death when their time comes should be recorded. Some regions require specific documentation of such decisions in a locally recognised format, for example, a 'Do Not Attempt Cardiorespiratory Resuscitation' order or 'Personal Resuscitation Plan'.

For people aged 18 years and over, elements of UK capacity legislation can support Advance Care Planning for those who have capacity for specific decisions, so that their wishes can be taken into account by the lead clinician should they lose capacity in the future ${ }^{20}$

- Advance Decision to Refuse Treatment

- Appointment of a Personal Health and Welfare Lasting Power of Attorney

- Support with best-interests decision-making from the Court of Protection

- The mode of death for this group is more likely to be gradual, most often with significant respiratory failure compounded by atelectasis and variable infection all of which may contribute to symptoms that will need to be addressed to ensure comfort at all times and explained to the family. Families may get upset about the length of time that the dying process can take. Being alongside them at this difficult stage of their child's journey and continuing to offer explanation and support is an important role of the clinical team and much appreciated by families.

\section{Decision-making frameworks}

All decision-making must be within an ethical and legal framework. In the UK clinicians are bound to follow the 2010 General Medical Council guidance on treatment and care towards the end of life that includes specific guidance on decision-making for children and young people ${ }^{23}$ and also the Equality Act $(2010)^{24}$ that includes disability and age among the protected characteristics that must not be used as a reason to treat some people worse than others. The Children Act (1989 and 2004) applies throughout the UK and includes a sevenpoint welfare checklist that must underpin any decisions made in the courts or best interests decisions about children and young people up to 18 years of age. ${ }^{25}$ In England and Wales those aged 16 years or more come under the 2005 Mental Capacity Act (MCA) that defines tests of capacity and sets out a minimum nine-point checklist for estimating the best interests of a person who lacks capacity. ${ }^{26}$

The process of decision-making as well as the actual decision should be written in the medical record and also in any family held care plan, so that in the event of a healthcare emergency it is clear to all who may be involved as to what has been discussed and decided, in the child's best interests. 
Figure 2 Red flags that dying and death are significant possibilities in children and young people who are medically frail.

\section{Increased frequency of:}

- time spent unwell

- biomarkers indicating relentless progression of disease process despite best treatment

- severe infections, taking longer to respond to treatment

- admissions to hospital and/or to paediatric intensive care

- feeding difficulties and swallowing dysfunction

- need for suction to clear upper airway due to decreased ability to clear own secretions

- treatment-resistant seizures

- agitation

- pain, which may be non-specific and no cause may be identified despite thorough clinical assessment

- changes in sleep, behaviour and personality

- 'control centre malfunction' as evidenced by intermittent or continuous autonomic dysregulation with variations in temperature, breathing, skin colour and sweating that are not explained by medically identifiable causes such as sepsis

Figure 3 Tips to consider when planning a conversation about the possibilities of dying and death of a child or young person.
- Always actively listen to the child or young person, check what they know and understand at every step

- Always actively listen to parents and carers, mindful that each may have a different view and have different needs in terms of how information is shared, understood and assimilated

- Seek permission to share difficult information and check that the setting and circumstances are as supportive as can be

- Give permission for others to be present as needed e.g. a grandparent, advocate or friend

- Don't be afraid of silence. This is an important component of active communication, giving time for reflection and assimilation of information

- Repeat important information and follow up in writing for the family and key involved professionals with consent

- Consider the needs of brothers and sisters and other family members and offer support in communicating with the wider family

- Involve the multidisciplinary team: general practitioner, therapists, specialist children's nurses etc. It is essential for the team around the child to be aware, with consent, about the information that has been shared to avoid misunderstandings

- Ensure prompt follow up, which may be with a different member of the team, to check understanding of what has been said and to offer support

- Avoid absolutes. Trying to predict length of life and timing of events is fraught with difficulties although many families will push for this. Remain humble about what is known and what is not

- Assure the family and carers of ongoing attention to symptoms and support

- Be proactive in predicting symptoms and scenarios that might arise and ensure there is a robust care plan in place and that any medication that may be required is easily accessible and available should an emergency arise

- Remember that it is discriminatory to put in place a 'Do not attempt cardiopulmonary resuscitation' order when an arrest is not an event that is anticipated.

- Discussing the possibility of sudden or 'unexpected death' does not mean that active treatment needs to stop. The child or young person can still receive full resuscitation and intensive care as required for as long as this is appropriate for them and has a chance of being successful. A positive statement about this should be included in the medical record and family-held care plan to protect the right to full and active treatment.

- Supporting families through uncertainty, where there is a range of outcome possibilities, although tricky for clinicians is important for families, who value supportive honesty above all else

- Being there alongside the child or young person and their parents and carers on their journey is as important as medicines in the overall therapeutic milieu and should not be undervalued

- Be aware of the stages of the grieving process that families may encounter when they receive difficult news, including disbelief, anger, guilt, bargaining, searching, fighting, sadness and in time, acceptance

- Be mindful of one's own feelings and emotions as a professional and do not be afraid to seek supervision and support. We are not always good at looking after ourselves as practitioners but we are no good to those we serve if we neglect to do so 
Figure 4 Checklist if dying and death may be possible.

- If death is a possibility, have you:

- Exhausted all expert assessments and treatment options for the child or young person? - Offered and obtained a second opinion or further expert opinions?

- Discussed the possibilities of dying and death with the child, young person and their family?

- If not, do this at the earliest opportunity to ensure inclusion in decision-making about end of life care

- Discussed plans fully with the child or young person's general practitioner?

- Discussed with the local lead paediatrician for Child Death Reviews to ensure a robust plan in keeping with local arrangements?

- If death is probable, you must inform the Coroner. Coroners vary, but increasingly the default position is that they want to know in advance about all children and young people under 18 years of age where death is likely. Let them know about any family-held care plans that state to 'allow a natural death' (or equivalent) and all 'Do Not Attempt Cardio-Pulmonary Resuscitation' documentation.

- If death is imminent, have you:

- Discussed with the child or young person and with their parents and carers their preferences about:

- Place of care and place of death;

- Who to call to say goodbye;

- Spiritual needs (never be afraid to ask. Even those who do not practice a regular religion may welcome spiritual support at this time);

- Choice of funeral home or undertaker. Advance warning is welcomed. Remember that many find the death of a child difficult too. Many will waive the fee for a child's funeral;

- Taking pictures, hand and foot prints as memories;

- Post mortem investigations.

- Have you:

- Planned ahead about who will be available to verify death e.g. general practitioner, specialist nurse, paediatrician, hospice doctor etc.

- Discussed post mortem wishes with the family and with the Coroner

- When death occurs:

- Death must be verified as per regulatory requirements (medical/nursing)

- Inform the Coroner about the fact of death

Offer spiritual support

Support family to link with the funeral care provider

Inform the family of the local arrangements for registering the death

Notify the local lead paediatrician for Child Death Reviews

Ensure completion of the Death Certificate if the Coroner has agreed to this

See also

http://www.togetherforshortlives.org.uk/professionals/resources/2779 end of life planning pr ompt sheets 2012

\section{Advance Care Planning with and for children under 16 years of age}

In UK law, children under 16 years of age are presumed to be incompetent to make their own decisions, although legal mechanisms exist that allow them to demonstrate their competence for specific decisions, for example, Fraser guidelines and Gillick competence test. ${ }^{27}$ While legally competent to make some decisions about themselves, young people face the extra challenges of adolescence including emerging and variable maturity and concrete thinking. The paediatrician, mindful of these complexities, should refer to the Children Act (1989 and 2004) welfare checklist ${ }^{25}$ to guide any decision made by, with or on behalf of children and young people in their best interests.

\section{Advance Care Planning with and for 16-year-olds and} 17 -year-olds and transition issues

There is a presumption in law in England and Wales that 1617 -year-olds have capacity to consent to treatment and can refuse some treatments. For those assessed to lack capacity, a person with parental responsibility, usually a parent, should be consulted by the clinician who will make a decision in the young person's best interests. Also, the Children Act (1989 and 2004) allows a parent to consent to treatment as for a younger child. It may be necessary to seek legal advice in case of uncertainty or disagreement.

In Scotland, 16-year-olds are considered to have capacity and can consent or withhold consent for themselves in the same way as a person 18 years of age or over in England and Wales under the MCA. For a young person in Scotland assessed to lack capacity for specific decisions, a power of attorney may be appointed by application to the Office of the Public Guardian (Scotland). ${ }^{28}$

In North-East England, a collaboration of palliative care physicians and paediatricians produced an all-age suite of support tools for decision-making and recording that is also being adopted in other regions. ${ }^{29}$ This overcomes difficulties that otherwise might arise at transition between children's and adult services, where 'best interests' may be differently defined.

Whatever process is adopted, it is essential to be mindful of the MCA best interests process for all young people over 16 years of age who lack capacity for a specific decision at a specific time and in specific circumstances.

\section{CONCLUSIONS}

In the face of increasing numbers of children with life-limiting conditions, paediatricians need to be well prepared to plan 
ahead for clinical scenarios that might arise, to recognise when unexpected or expected death may be possible and to discuss risks openly with families. This allows the child where possible and their parents and carers, to express and record their wishes and preferences and for conversations to be had between the family and multidisciplinary team about appropriate levels of interventions. Increasing the number of conversations about dying and death with families and improving recording of wishes and decision-making using a pACP framework will facilitate future research to explore pACP more thoroughly, with the hope of making the most difficult journey of all for families a little more bearable.

\section{Competing interests None.}

Provenance and peer review Commissioned; externally peer reviewed.

\section{REFERENCES}

1 Lotz JD, Jox RJ, Borasio GD, et al. Pediatric Advance Care Planning: A systematic review. Pediatrics 2013;131:e873-80.

2 Horridge KA. Dying, death, disabled children and young people: how might we be better prepared? Child Care health Dev 2012:38:3-5.

3 Teno JM, Nelson HL, Lynn J. Advance care planning: priorities for ethical and empirical research. Hasting's Cent Rep 1994:24:532-6.

4 Child Health Reviews - UK. RCPCH 2013. http://www.rcpch.ac.uk/child-healthreviews-uk/programme-findings/programme-findings (accessed 26 Aug 2014).

5 Lyon ME, Garvie PA, Briggs L, et al. Development, feasibility, and acceptability of the Family/Adolescent-Centered (FACE) Advance Care Planning intervention for adolescents with HIV. J Palliat Med 2009:12:363-72.

6 Lyon ME, Jacobs $S$, Briggs $L$, et al. Family-centered advance care planning for teens with cancer. JAMA Pediatr 2013:167:460-7.

7 Lyon ME, Garvie PA, McCarter R, et al. Who will speak for me? Improving end-of-life decision-making for adolescents with HIV and their families. Pediatrics 2009;123:e199-206. http://www.pediatrics.org/cgi/content/full/123/2/e199 (accessed 26 Aug 2014).

8 McBride D. Advanced care planning discussions with adolescents and young adults with cancer. J Pediatr Nurs 2013;28:406-7.

9 Walter JK, Rosenberg AR. Feudtner C. Tackling taboo topics: how to have effective advanced care planning discussions with adolescents and young adults with cancer JAMA Pediatr 2013:167:489-90.
10 Taylor B. We must give children a voice in advance care planning. BMJ 2012;345: e5111.

11 Barfield RC, Brandon D, Thompson J, et al. Mind the child: using interactive technology to improve child involvement in decision making about life-limiting illness. Am J Bioeth 2010;10:28-30.

12 Zinner SE. The use of pediatric advance directives: a tool for palliative care physicians. Am J Hosp Palliat Care 2009;25:427-30.

13 Brook L, Hain R. Predicting death in children. Arch Dis Child 2008:93:1067-70.

14 Marcin JP, Pollack MM, Patel KM, et al. Prognostication and certainty in the pediatric intensive care unit. Pediatrics 1999;104(4 pt 1):868-73.

15 Durall A, Zurakowski D, Wolfe J. Barriers to conducting advance care discussions for children with life-threatening conditions. Pediatrics 2012;129: e975-82. http:/ www.pediatrics.org/cgi/content/full/129/4/e975 (accessed 26 Aug 2014).

16 Hammes BJ, Klevan J, Kempf M, et al. Pediatric advance care planning. J Palliat Med 2005;8:766-73.

17 Jefferson LS, White BC, Louis PT, et al. Use of the Natural Death Act in pediatric patients. Crit Care Med 1991:19:901-5.

18 Mitchell S, Dale J. Handle with care: advance care planning for children and young people with palliative care needs. BMJ Support Palliat Care 2013:3:128.

19 Mitchell S, Plunkett A, Dale J. Use of formal advance care planning documents: a national survey of UK Paediatric intensive Care Units. Arch Dis Child 2014;99:327-30

20 Fraser J, Harris N, Berringer J, et al. Advanced care planning in children with life-limiting conditions - the Wishes Document. Arch Dis Child 2010:95:79-82.

21 Nesbitt V, Kirkpatrick M, Pearson G, et al. Risk and causes of death in children with a seizure disorder. Dev Med Child Neurol 2012:54:612-17.

22 Horridge KA. Assessment and investigation of the child with disordered development. Arch Dis Child Educ Pract 2011:96:9-20.

23 Treatment and care towards the end of life: Good practice in decision making. General Medical Council. 2010. London. http://www.gmc-uk.org/guidance/ethical_ guidance/end_of_life_care.asp (accessed 26 Aug 2014).

24 Equality Act (2010): http://www.legislation.gov.uk/ukpga/2010/15/contents (accessed 26 Aug 2014).

25 http://www.legislation.gov.uk/ukpga/1989/41/section/1 (accessed 26 Aug 2014).

26 Mental Capacity Act (2005): http://www.legislation.gov.uk/ukpga/2005/9/contents (accessed 26 Aug 2014)

27 Wheeler R. Gillick or Fraser? A plea for consistency over competence in children. BMJ 2006;332:807.

28 Adults with Incapacity (Scotland) Act 2000: http://www.scotland.gov.uk/Topics/ Justice/law/awi (accessed 26 Aug 2014).

29 Deciding right: an integrated approach to making care decisions in advance with children, young people and adults. Newcastle-upon-Tyne: NHS north east SHA. January 2012. http://www.cnne.org.uk/end-of-life-care---the-clinical-network/ decidingright (accessed 26 Aug 2014). 